\title{
On the Emergence, Development and Prospect of Financial Mathematics
}

\author{
Xiaogang Yang \\ Chengdu Normal University, Chengdu, China \\ Email:930761897@qq.com
}

How to cite this paper: Yang, X.G. (2017) On the Emergence, Development and Prospect of Financial Mathematics. Modern Economy, 8, 1129-1134.

https://doi.org/10.4236/me.2017.89078

Received: September 4, 2017

Accepted: September 22, 2017

Published: September 25, 2017

Copyright $\odot 2017$ by author and Scientific Research Publishing Inc. This work is licensed under the Creative Commons Attribution International License (CC BY 4.0).

http://creativecommons.org/licenses/by/4.0/

\begin{abstract}
Since its emergence in 1980s, financial mathematics has developed into an interdisciplinary subject with independent theoretical system. On the one hand, financial mathematics has become the key technology that can be seen everywhere in finance. On the other hand, the development of Finance provides an important platform for the application of mathematics. The purpose of this paper is to analyze and summarize the emergence and development of financial mathematics, and to analyze the future of financial mathematics.
\end{abstract}

\section{Keywords}

Financial Mathematics, Emergence, Development, Prospect

\section{(c) (i) Open Access}

\section{The Emergence of Financial Mathematics}

Financial mathematics was an interdisciplinary subject of mathematics and finance in the 1980s. It is the study of financial market risk assets, and its purpose is to use effective mathematical tools to reveal the essential features of finance, so as to achieve the optimal strategy for a potential risk of contingent claim pricing and risk averse. Its history can be traced back to 1900, the French mathematician Basch Lee E's doctoral dissertation, "speculative theory". In this paper, for the first time using Brown Bachelier motion to describe the stock price changes, this was the finance development, especially lays a theoretical foundation for the modern option pricing theory. However, his work has not received much attention from the financial mathematics community. Until 1952, Markowitz's doctoral dissertation "portfolio selection" proposed mean-variance model, the establishment of portfolio theory, and a mathematical theory of finance. Based on Markowitz work, 1973 Black and Scholes got famous option pricing formula, and won the 1997 Nobel prize in economics study. It provides 
a satisfactory answer to an important practical problem, namely, to seek fair prices for European call options. The latter two discoveries promoted the development of mathematical research to finance, and gradually formed a new cross subject, financial mathematics [1].

Financial mathematics is a frontier subject of mathematics and finance that has developed rapidly on the basis of the two Wall Street revolution. The core of the study is to study the optimal portfolio selection theory and asset pricing theory in the uncertain stochastic environment. Arbitrage, optimization and equilibrium are the basic economic ideas and three basic concepts of financial mathematics. Internationally, this subject has been developed for more than 50 years. Especially in recent years, many experts in the field of financial mathematics have been able to prove, simulate and perfect it in the efforts of many experts and scholars. The rapid development of financial mathematics has led to the rapid innovation of financial products in modern financial markets, making the scope and level of financial transactions more abundant and diverse. This new discipline also has close relationship with China's financial reform and development, and its development prospects in China are limitless.

\section{The Development of Financial Mathematics}

As early as in 1990, French mathematician Bacheri described the stock as Brown's movement in his doctoral thesis "speculative theory". This is also the first rigorous mathematical description of the Brown movement. This theory lays the foundation for the future development of financial mathematics, especially the establishment of option theory. But this work has not attracted the attention of the financial mathematics for a long time. The name of the subject of financial mathematics didn't appear until the late 1980s. It is the portfolio theory mark position (H. Kowitz 1990 Nobel prize in Economics) option pricing theory and Scholes-Merton (M. Scholes-R. Merton. 1997 won the Nobel Prize in Economics), the direct result of the two revolution of Wall Street. International calls it mathematical finance [2].

Financial mathematics originated in the early twentieth Century by French mathematician Basch Lee $\mathrm{E}$ in his doctoral thesis, the principle of speculation, depicting Brown's movements in stock prices. Although 1905 Einstein also did the study, but this new approach was not able to attract more people's attention, until 1950, Seoul by SA Liao statistician Savage finally found the great significance of this practice, and began to do comprehensive research on financial mathematics, financial mathematics which finally ushered in the development of the heyday modern finance which officially opened the curtain.

Modern financial mathematics grew up in the context of the two Wall Street revolution. The achievements of the first revolution are embodied in the study of the theory of static portfolio theory. In 1952 Marco Chavez presented portfolio mean variance model based on the theory of the investment risk and return the quantitative characterization, which pioneered the use of mathematical methods 
to study the financial problems of precedent. His model, however, calculates the covariance of the prices of each risky asset, which is very large. The second Wall Street revolution evolved from a static decision to a dynamic one. In 1970 the collapse of the Bretton Woods Agreement, the floating exchange rate instead of a fixed exchange rate, many financial derivatives such as options, futures are randomly generated, the introduction of these financial derivatives are mainly for financial risk management, and to make scientific and effective risk on the tube on the need for scientific pricing of derivatives. Brown makes a motion model of Bachelier twins: the birth of financial engineering option pricing mathematics stochastic process with continuous time and continuous time. The introduction of mathematical tools is mainly for financial risk management, and to make scientific and effective risk on the tube on the need for scientific pricing of derivatives. Shortly thereafter, Merton used another rigorous mathematical approach to derive the pricing formula and to extend it. The option pricing formula has brought unprecedented convenience to financial traders and bankers in the transaction of financial derivatives, and the rapid development of options trading has quickly become the main content of the world financial market. The theory of Black, Hughes and Morton has become a milestone in modern financial economics, and is still an important source of modern financial theory [3].

\section{The Future of Financial Mathematics}

With the further development and perfection of financial market, people find complete information of all the previous research on the financial model assumed that investors can get the market, but investors can only depict the observed system state price process itself, the drift coefficient of Brown motion and dynamic assets can not be observed, that investors can only get some market information. Therefore, many scholars have systematically studied the investment and consumption problems based on incomplete information using various mathematical methods, and have made some progress.

\subsection{Saddle Theory}

The introduction of saddle theory is the latest research achievement of modern financial theory. In 1977, Harrison (Harrison J. M.) and Corey Poos (Kreps S. R.) proposed the martingale method of option pricing theory, they use martingale measure concept in martingale theory characterizing no arbitrage and incomplete markets, and use the equivalent martingale measure on option pricing and hedging or hedge. Saddle method advocated by Karatza. S and Shreve, directly to the saddle theory into modern financial theory, the pricing problem of using the concept of equivalent martingale measure of derivative securities, the result can not only reveal the operation of the financial market, but also can provide a set of effective algorithms, pricing and risk management of complex problem solving financial derivative products.

Another function of the saddle theory in the study of financial theory is that it 
can solve the problem of the pricing of derivative securities when the financial market is incomplete, so that the modern financial theory has made a breakthrough progress". At present, the derivative securities pricing theory based on saddle method is dominant in modern financial theory, but it is still a blank in our country.

\subsection{Intelligent Optimization}

The intelligent optimization method (genetic algorithm, simulated annealing algorithm, artificial neural network and wavelet analysis) and combine traditional methods, applied to the risk control and investment decision problem is another has more broad research areas, provides a wide range of research topics for us. The international research on this aspect has made preliminary achievements, and there are a large number of scholars in China devoted to this research. Due to the development of this field is relatively late, there are many problems have not been solved yet, but we still believe that the financial experts, mathematicians and artificial intelligence experts to work together in this emerging field of study will be able to achieve a breakthrough.

\subsection{Differential Game Theory}

The application of differential game method to the option pricing problem and the investment decision problem is another important aspect of the development of modern financial theory, and some achievements have been made. When the financial market does not satisfy the steady-state assumption or abnormal fluctuations in stock prices, often do not obey the geometry Brown motion, then using the method of random dynamic model of securities investment decision problems both in theory, or in fact there is deviation from. Using the differential game method to study the financial decision problem can relax the hypothesis. The uncertainty disturbance is assumed to be a hostile one, and the optimal investment strategy with strong robustness can be obtained by optimizing the worst case. In addition, the Behrman equation for differential games is a first-order partial differential equation, which is much simpler than the two order partial differential equations for stochastic control problems. Therefore, the application of differential game method to the study of financial problems has broad application prospects.

\subsection{Stochastic Optimal Control Theory}

An important application field of financial theory is to solve the stochastic problem of continuous time, and the important means to solve this problem is stochastic optimal control theory. Stochastic optimal control was developed in the late 1960s and early 70s. Mathematicians applied the Behrman optimization principle and developed new mathematical research fields using measurement theory and functional analysis. 1971 Merton (Merton) using continuous time methods and discuss the consumption portfolio problem, Brock (Brock) and Millman 
(Mirman) used in the discrete time case method to solve the problem of uncertain optimal economic growth. So far, the stochastic optimal control method has been applied to most financial fields and has broad prospects for development.

\subsection{Optimal Stopping Time Theory}

The theory of optimal stopping time is a very practical field in the system of probability theory. In recent years, many financial mathematicians combine this theory with modern portfolio theory, and have achieved good results. However, the research literature in this field is still not much, and the field is still in its infancy. Based on the optimal stopping theory, Moton A and Pliska S R studied the investment decision problem with fixed transaction costs, and gave a simplified algorithm for the investment decision making problem with two risk securities. In China, the research on this aspect is still rare. It is believed that the application of the optimal stopping theory to the study of investment decision problems and risk minimization problems will lead to greater progress.

\subsection{The Market Price Fluctuations}

The so-called price volatility, usually refers to the future price deviation from the expected value of the possibility. In financial economics, volatility is measured by standard deviations of returns, not by standard deviations of prices. For example, in the "B S model" and most of its generalizations, it is unreasonable to assume that the volatility of stock prices is constant. In order to more accurately describe the stock price change rules, must consider the following factors: the stock price volatility of stock price volatility and dependence; other random variables depend on the stock price may jump suddenly. Stochastic volatility models can reflect some of these factors, and are now highly valued. Such models assume that volatility obeys a stochastic process, such as geometric Brown motion.

\subsection{The Term Structure of Interest Rates}

In the B-S model, interest rates are given constants. In fact, the changes in interest rates are quite complex. The laws of interest rates vary in different properties and maturities, which is the term structure of interest rates. It can usually be expressed in the form of yield curves. The term structure of interest rate includes three theories: market expectation theory, market segmentation theory and investment preference theory, and liquidity preference theory. These theories explain the irregular changes in interest rates from different angles. In recent years, interest rate risk has become increasingly prominent, interest rate options and other interest rate derivative securities have been developed rapidly, and the mathematical model of the term structure of interest rates has been put forward.

\subsection{Emergency Issues}

Unexpected events can not be ignored in the financial field, such as the financial crisis in Southeast Asia in 1997, which has caused great losses to some countries. 
The prediction theory based on the traditional stationary random process is not applicable at all. Traditional theories may explain how the market took place in $95 \%$ of the time. However, if people admit that emergencies occur in the remaining $5 \%$ of the time, then the picture described by the traditional theory does not reflect the actual situation. Now we apply chaos theory and fractal theory to explain how the stock price soared and plummeted. The early warning of financial emergencies is often difficult because it involves many factors, quantification and alarm sensitivity, which is also an important field of financial mathematics research.

\subsection{American Option Problem}

Most of the options traded in the market are American options. The problem of Pricing American options is much more difficult than that of European options. Because American options can be executed at any time before maturity, this involves the optimal execution time of the expiration rights. In general, the optimal execution time of options is a very complicated problem and has not been well solved so far. If the method of partial differential equation is used to discuss the pricing of American options, the problem of the corresponding partial differential equation will become a "free boundary" problem, which is difficult to deal with mathematically. In general, no accurate analytical pricing formula of American option, and can only use numerical solution or approximate analytic solution, therefore, it has important practical significance of numerical methods for American options pricing development [4].

\section{Epilogue}

Financial mathematics is a new frontier subject which studies the law of financial operation by means of mathematical theories and methods. The core problem is portfolio selection and asset pricing theory under uncertain multiple periods. Arbitrage, optimality and equilibrium are three main concepts. The latest research results of financial mathematics are stochastic optimal control theory, saddle theory, differential game theory, optimal stopping time theory and intelligent optimization. The current problems and prospects of financial mathematics are mainly about American option, Asian option, interest rate structure, market price fluctuation and unexpected events.

\section{References}

[1] Zhang, Y. (2010) The Application of Economic Mathematics. Journal of Liaoning Teachers College (NATURAL SCIENCE EDITION), 19, 68-70.

[2] Xue, J.J. and Qiao, L.F. (2011) Current Situation and Development of Financial Mathematics. Journal of Daqing Normal University, 31, 80-83.

[3] Sun, Z.Q. and Liu, X.H. (2010) An Overview of Financial Mathematics and Its Prospect. Journal of Chongqing Academy of Arts and Sciences (NATURAL SCIENCE EDITION), 29, 24.

[4] Guo, C. (2011) A Review of Recent Advances in Financial Mathematics. Modern Trade and Industry, 23, 169. 
Submit or recommend next manuscript to SCIRP and we will provide best service for you:

Accepting pre-submission inquiries through Email, Facebook, LinkedIn, Twitter, etc. A wide selection of journals (inclusive of 9 subjects, more than 200 journals)

Providing 24-hour high-quality service

User-friendly online submission system

Fair and swift peer-review system

Efficient typesetting and proofreading procedure

Display of the result of downloads and visits, as well as the number of cited articles Maximum dissemination of your research work

Submit your manuscript at: http://papersubmission.scirp.org/

Or contact me@scirp.org 